\title{
Semi-active vibration control of high-speed rotor system with electrorheological bearing fluid
}

\author{
Rajasekhara Reddy Mutra $^{1}$, and Srinivas $\mathbf{J}^{{ }^{*}}$ \\ 1, Department of Mechanical Engineering, NIT Rourkela, 769008, Odisha, India
}

\begin{abstract}
Present work focuses on the use of electrorheological fluid (ERF) as a lubricant in the high speed turbocharger rotor supported on floating ring bearings. The rotor is analysed by finite element modelling with gyroscopic effects and bearing forces. The ERF contains one carrier fluid and active particles that react to external electric field, which induces a yield stress in the fluid increasing its viscosity. In order to control the rotor vibration amplitudes, the dynamic changes in the fluid viscosities at the inner and outer films of bearing are employed with external electric field. A case study of automotive turbocharger rotor is considered and the effect of semi-active control is illustrated on the dynamic response of the system.
\end{abstract}

\section{Introduction}

The turbocharger rotor basically consists of a turbine and compressor which are connected through a shaft supported on a journal bearing system. The working speed of the turbocharger is often very high, and even small unexpected vibrations could destroy a bearing and decreases the life service of the turbocharger. Therefore, a turbocharger rotor requires special attention through-out its operating life, in a similar manner as that of rotors of turbo-compressors and turbo-pumps. In practice, due to repetitive usage, various faults occur at different components of the system. This results in a high response and violent vibrations at critical speeds of operation. The primary consideration in the design of turbo machinery is to minimise and control of vibrations. Vibrations with large amplitudes are undesirable because it generates noise and cause rotor-stator rub resulting in unexpected failures. Vibration-based condition monitoring of such rotors is therefore very much essential.

Several earlier works [1-3] explained the stability analysis of high speed turbocharger rotor supported on the full floating ring bearings system. Vibration control in rotors is an active topic of research for several decades. The existing methods for rotor vibration control aim to suppress the out-of-balance force of the rotors. Different prevailing methods of controlling rotors are active, semi-active and passive. In active method, a direct force is exerted to restrict the motion of the rotor and often has electromagnetic actuator. In passive methods on the other hand, the damping property of the rotor system is enhanced. Another

\footnotetext{
* Corresponding author: srin07@yahoo.co.in
} 
way is to rely on fluid film to provide additional damping. Applications include using squeeze film damper for roller bearing to provide damping. The semi-active method of rotor vibration adjusts indirectly the bearing properties of the rotor system. Therefore, controllable bearings, or smart bearings, are considered to be one promising area. A comprehensive review on the composition of the magnetorheological fluids and effective parameters are explained in the literature [4]. Forte et al. [5]explained the design, theoretical modelling and the preliminary testing of the magnetorheological squeeze film damper. Kazakov et al.[6] developed a finite element model of the magnetorheological damper and the mutual influence of electromagnetic, hydrodynamic and thermal fields in the analysis is accounted. Wang et al. [7] identified the stiffness and damping characteristics of the of the magnetorheological fluid lubricated floating ring bearings by using identified Herschel-Bulk model. Wang et al.[8] measured the rotor dynamic coefficients of a controllable floating ring bearings. Here they obtain the controllability of the bearing by utilizing the magneto rheological fluid as lubricant along with the external magnetic field. Some earlier works [9-11] explained the vibration control studies on the rotor dynamics by using of different methods like active and passive vibration controls.

Some more works $[12,13]$ explained the application of the electrorheological fluids in machine tool elements and the automobile engine mount applications. Orsalia et al.[14] identified the stiffness and damping coefficients of journal bearing as function of applied electric field. Some earlier works $[15,16]$ experimentally investigated on journal bearings by considering the electrorheological fluid as lubricant. They proved that electrorheological fluids at high shear rate under constant temperature follows the Bingham model in realistic bearings. The vibration control of high speed rotor systems by considering electrorheological fluids are explained by the literature [17-19].

The present work focus on the use of electrorheological fluid (FRF) as a lubricant in the high speed turbocharger floating ring bearings. The ERF contains one carrier fluid and active particles that react to external electric field, which induces a yield stress in the fluid increasing its viscosity. In order to control the rotor vibration amplitudes, the dynamic changes in the fluid viscosities at the inner and outer films of bearing are employed with external controlled field. The paper organised as follows.

\section{Mathematical modelling of rotor bearing system}

Using the Timoshenko beam theory a simplified rotor system is developed. For dynamic analysis of the rotor system a convergence study is carried out to select the number of elements and it was found that eight elements configuration performing nicely. As shown in Figure 1, for eight shaft elements, nine nodes are required for discretization. Nodes 1 and 9 shows the disks location represents as the lumped masses. Whereas the node 3 and 7 represents the floating ring bearing location. Each node as four degree of freedom (DOF) including tow bending deflections $\left(\mathrm{U}_{\mathrm{x}}, \mathrm{U}_{\mathrm{y}}\right)$ and corresponding slopes $\left(\theta_{\mathrm{x}}, \theta_{\mathrm{y}}\right)$.

The rotor equations of motion can be expressed as:

$$
\mathbf{M} \ddot{u}+(\mathbf{C}+\Omega \mathbf{G}) \dot{u}+\mathbf{K} u=F_{u g}+F_{h i}
$$




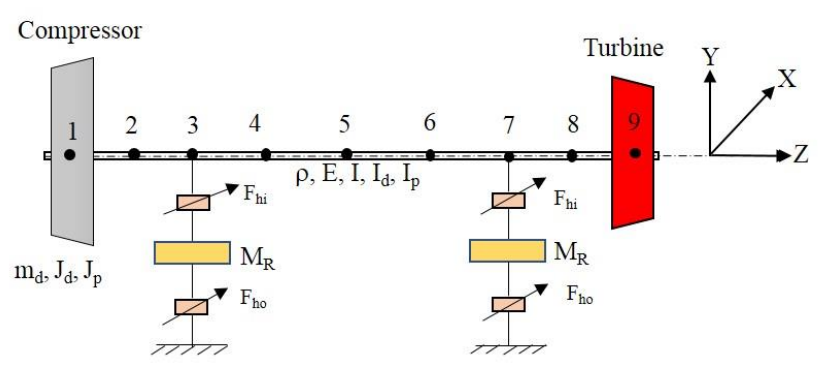

Fig. 1. Finite element model.

Here $\mathbf{M}, \mathbf{C}, \mathbf{G}$ and $\mathbf{K}$ represent the equivalent mass, damping, gyroscopic and stiffness matrices of size $\mathrm{N} \times \mathrm{N}$. also $\mathrm{u}$ is the $\mathrm{N} \times 1$ displacement vector, $\mathrm{F}_{\mathrm{ug}}$ is unbalance and gravity force vector at the discs, $\mathrm{F}_{\mathrm{hi}}$ is hydrodynamic fluid force of the inner oil film at bearing nodes.

The equation of motion of the floating ring within the bearing is represented as:

$$
\mathbf{M}_{\mathbf{R}} \ddot{u}_{R}=F_{h o}-F_{h i}
$$

Where $u_{R}$ represents the $4 \times 1$ displacement vector of the floating ring at two bearings, $\left[\mathrm{M}_{\mathrm{R}}\right]$ is the corresponding mass matrix of the rings with the size of $4 \times 4 . F_{h o}$ and $F_{h i}$ are the outer and inner oil film component force vectors. By combining the system of equations for rotor and bearing, the assembled equations are represented as:

$$
\hat{\mathbf{M}} \ddot{\hat{u}}+\hat{\mathbf{C}} \dot{\hat{u}}+\hat{\mathbf{K}} \hat{u}=\hat{F}
$$

Where

$\hat{\mathbf{M}}=\left[\begin{array}{cc}\mathbf{M} & 0 \\ 0 & \mathbf{M}_{\mathbf{R}}\end{array}\right], \hat{\mathbf{C}}=\left[\begin{array}{cc}\mathbf{C}+\Omega \mathbf{G} & 0 \\ 0 & 0\end{array}\right], \quad \hat{\mathbf{K}}=\left[\begin{array}{cc}\mathbf{K} & 0 \\ 0 & 0\end{array}\right] \quad$ are effective $(\mathrm{N}+4) \times(\mathrm{N}+4)$ square matrices, while $\hat{u}=\left[\begin{array}{ll}u & u_{R}\end{array}\right]^{T}$ is $(\mathrm{N}+4) \times 1$ vector of displacements and $\hat{F}=\left[\begin{array}{ll}F_{u g}+F_{h i} & F_{h 0}-F_{h i}\end{array}\right]^{T}=\hat{F}_{u g}+\hat{F}_{b}$ is resultant $(\mathrm{N}+4) \times 1$ vector of unbalance and floating ring bearing forces.

\subsection{Floating ring bearing forces}

The nonlinear floating ring bearing force components are expressed as [20]:

$$
\begin{gathered}
\left\{\begin{array}{l}
F_{i x} \\
F_{i y}
\end{array}\right\}=\mu_{i}\left(\Omega_{j}+\Omega_{r}\right) R_{j} L_{i}\left(\frac{R_{j}}{C_{1}}\right)^{2}\left(\frac{L_{i}}{2 R_{j}}\right)^{2}\left\{\begin{array}{l}
f_{i x} \\
f_{i y}
\end{array}\right\} \\
\left\{\begin{array}{l}
F_{o x} \\
F_{o y}
\end{array}\right\}=\mu_{o} \Omega_{r} R_{o} L_{o}\left(\frac{R_{o}}{C_{2}}\right)^{2}\left(\frac{L_{o}}{2 R_{o}}\right)^{2}\left\{\begin{array}{l}
f_{o x} \\
f_{o y}
\end{array}\right\}
\end{gathered}
$$

where $f_{i x}, f_{i y}$ and $f_{o x}, f_{\text {oy }}$ respectively the component forces on the journal and bearing. 


\subsection{Characteristics of electrorheological (ER) fluids}

In this work the electrorheological (ER) lubricant flow behaviour is demonstrated by the continuous Bingham model, which is propose by Dorier and Tichy [21]. In electrorheological fluids the electric field is presence it makes particles to orient themselves along the electric field line. This process makes the fluid more viscous, consequently transferring from liquid to a semi-solid state. The continuous Bingham model can be expressed as follows: [19]

$$
\mu(\dot{v})=\mu_{0}+\frac{2 \gamma_{0}}{\pi \dot{v}} \tan ^{-1}\left(\frac{\dot{v}}{\dot{v}_{0}}\right)
$$

Where $\mu_{0}$ is viscosity of electrorheological fluid, $\dot{v}$ is the shear starin rate and $\gamma_{0}$ represents the yield stress parameter which can be expressed as follows:[22]

$$
\gamma_{0}(E)=B E^{C}
$$

Where $B$ and $C$ are the electrorheological fluid parameter and electrorheological field parameter, respectively. If $V$ is imposed voltage in volts and $h_{f}$ is the nominal fluid film thickness, then the electric filed is expressed as follows:

$$
E=\frac{V}{h_{f}}
$$

\section{Results and discussions}

The resultant system of nonlinear equations are solved by fourth-order Runge-Kutta time integration method with all zero initial conditions. The programs are executed on Intel Core-i7, $3.40 \mathrm{GHz}$ processor with $4 \mathrm{~GB}$ RAM. Dimensional data of the rotor-bearing system considered is depicted in Table 1.

Initially the analysis is carried out by without considering the electrorheological fluid effect on rotor-bearing system. It is observed that there are three dominant peaks occurring at frequencies $51.27 \mathrm{~Hz}, 88.2 \mathrm{~Hz}$ and $416.6 \mathrm{~Hz}$. Here, the peak obtained at $416.6 \mathrm{~Hz}$ corresponds to the critical speed of the rotor operating at 25,000 rpm. Further, the analysis is carried out by considering the electrorheological fluid effect on rotor-bearing system. The electrorheological effect is considered at the inner film of the floating ring bearing because it affects the dynamics considerably. The outer film viscosity variation is relatively small.

Table 1. Data used for rotor-bearing system [23].

\begin{tabular}{|l|c|}
\hline \multicolumn{1}{|c|}{ Properties } & Value \\
\hline Density of shaft material $\rho\left(\mathrm{kg} / \mathrm{m}^{3}\right)$ & 7860 \\
\hline Mass of Left Disc, $\mathrm{M}_{\mathrm{DL}}(\mathrm{kg})$ & 0.118 \\
\hline Mass of Right Disc2, MDR $(\mathrm{kg})$ & 0.326 \\
\hline Diameter moment of inertia of the Left Disc, IDL $\left(\mathrm{kgm}^{-2}\right)$ & $3.27 \times 10^{-5}$ \\
\hline Diameter moment of inertia of the Right Disc, IDR $\left(\mathrm{kgm}^{-2}\right)$ & $7.70 \times 10^{-5}$ \\
\hline Polar moment of inertia of the Left Disc, JDL $\left(\mathrm{kgm}^{-2}\right)$ & $4.40 \times 10^{-5}$ \\
\hline Polar moment of inertia of the Right Disc, JDR $\left(\mathrm{kgm}^{-2}\right)$ & $8.10 \times 10^{-5}$ \\
\hline Diameter of shaft, $\mathrm{D}_{\mathrm{sh}}(\mathrm{m})$ & $11 \times 10^{-3}$ \\
\hline Length of the shaft, $\mathrm{L}(\mathrm{m})$ & $105 \times 10^{-3}$ \\
\hline Length of Left bearing from left end, $\mathrm{L}_{1}(\mathrm{~m})$ & $33 \times 10^{-3}$ \\
\hline Length of Right bearing from left end, $\mathrm{L}_{2}(\mathrm{~m})$ & $72 \times 10^{-3}$ \\
\hline Young's modulus, E $(\mathrm{GPa})$ & 200 \\
\hline
\end{tabular}




\begin{tabular}{|l|c|}
\hline Viscosity of FRB-1 (centi-Poise) & 6.4 \\
\hline Viscosity of FRB-2 (centi-Poise) & 4.9 \\
\hline Floating ring mass (grams) & 7.2 \\
\hline Inner radial clearance of FRB-1 (m) & $34 \times 10^{-6}$ \\
\hline outer radial clearance of FRB-1 (m) & $74 \times 10^{-6}$ \\
\hline Inner radial clearance of FRB-2 (m) & $34 \times 10^{-6}$ \\
\hline outer radial clearance of FRB-2 (m) & $74 \times 10^{-6}$ \\
\hline
\end{tabular}

The properties of the electrorheological lubricant is shown in the Table. 2

Table 2. Electrorheological fluid properties [19]

\begin{tabular}{|l|c|}
\hline \multicolumn{1}{|c|}{ Parameter } & Value $/$ range \\
\hline ER fluid parameter, B, $\mathrm{Pa}(\mathrm{m} / \mathrm{V})^{\mathrm{C}}$ & $6.619 \times 10^{-13}$ \\
\hline ER fluid field parameter, C & 2.18 \\
\hline Applied voltage $(\mathrm{V})$ & 600 \\
\hline Applied electric field, E $(\mathrm{kV} / \mathrm{mm})$ & $0,2,4,6$ \\
\hline ER lubricant viscosity, $\mu\left(\mathrm{N} \mathrm{s} / \mathrm{m}^{2}\right)$ & 0.0816 \\
\hline
\end{tabular}

Fig. 2 show the time history and FFT of the left bearings at a rotor speed of $25000 \mathrm{rpm}$. It is observed that the first two peaks amplitudes are reducing and the third peak amplitude is maintained constant value. The electrorheological effect is clearly seen in the response of the system.
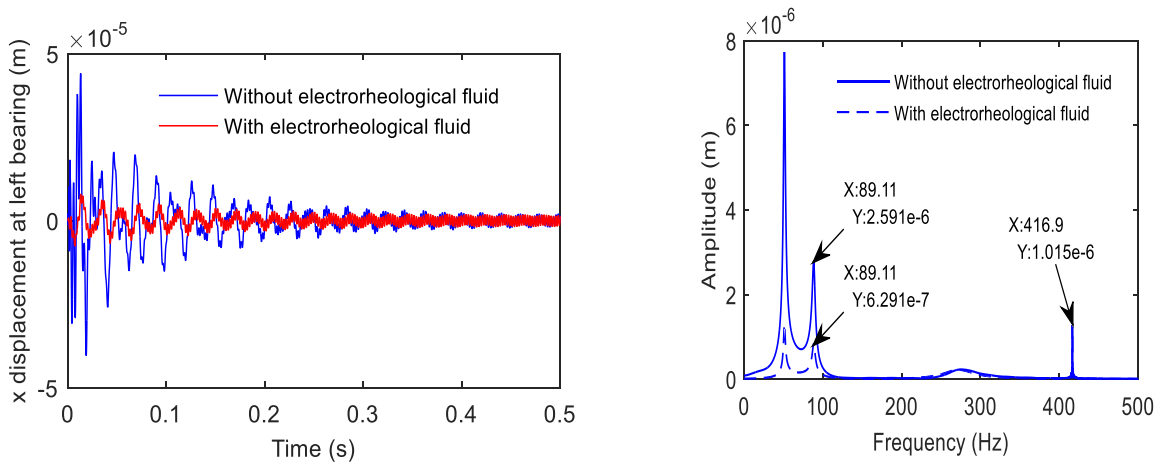

Fig. 2. Time response and FFT plots at left bearing.

Further, the response of the system is studied for different applied electric field strength (E) of the ER fluid. Table 3 shows the first three response amplitudes of left bearing with electrorheological fluid at a rotor speed of $25,000 \mathrm{rpm}$.

Table 3. Effect of applied electric filed on first three response amplitudes.

\begin{tabular}{|c|c|c|c|}
\hline $\mathbf{E}=\mathbf{0} \mathbf{~ k V} / \mathbf{m m}$ & $\mathbf{E}=\mathbf{2} \mathbf{~ k V} / \mathbf{m m}$ & $\mathbf{E}=\mathbf{4} \mathbf{~ k V} / \mathbf{m m}$ & $\mathbf{E}=\mathbf{6} \mathbf{~ k V} / \mathbf{m m}$ \\
\hline $7.021 \times 10^{-6} \mathrm{~mm}$ & $5.125 \times 10^{-6} \mathrm{~mm}$ & $1.318 \times 10^{-6} \mathrm{~mm}$ & $3.534 \times 10^{-7} \mathrm{~mm}$ \\
\hline $2.622 \times 10^{-6} \mathrm{~mm}$ & $1.118 \times 10^{-6} \mathrm{~mm}$ & $8.38 \times 10^{-7} \mathrm{~mm}$ & $9.443 \times 10^{-8} \mathrm{~mm}$ \\
\hline $1.235 \times 10^{-6} \mathrm{~mm}$ & $1.231 \times 10^{-6} \mathrm{~mm}$ & $1.282 \times 10^{-6} \mathrm{~mm}$ & $1.274 \times 10^{-6} \mathrm{~mm}$ \\
\hline
\end{tabular}


It is observed that, as the applied electric field (E) increases, the first two response amplitudes are reducing while the third peak amplitude maintains almost constant value. The response of the system is influenced by the applied electric field (E).

\section{Conclusion}

Present work focuses on the use of electrorheological fluid (ERF) as a lubricant in the high speed turbocharger rotor supported on floating ring bearings. In order to control the rotor vibration amplitudes, the dynamic changes in the fluid viscosities at the inner film of bearing were employed with an externally controlled field. Initially, the response of the system was obtained without the effect of rheological fluid lubricant forces. Afterwards the response of the system was studied with the electrorheological fluid effect by several parametric studied. The effect of the applied electric field (E) on the response of the system was found to be large and concluded that as the applied electric field increases, the amplitudes in the response get reduced. The effectiveness of this semi-active control concept can be enhanced by considering additional operating conditions like temperature as in a turbocharger rotor system. An experimental set-up for validation is further required.

\section{References}

[1] H. Zhang, Z. Shi, S. Zhang, F. Gu, A. Ball, Sci. Res. Essays 8, 1495 (2013)

[2] R.G. Kirk, A.A. Alsaeed, E.J. Gunter, Tribol. Trans. 50, 427 (2007)

[3] H. Zhang, Z.Q. Shi, D. Zhen, F.S. Gu, A.D. Ball, J. Phys. Conf. Ser. 364, 012032 (2012)

[4] M. Ashtiani, S.H. Hashemabadi, A. Ghaffari, J. Magn. Magn. Mater. 374, 716 (2015)

[5] P. Forte, M. Paternò, E. Rustighi, Int. J. Rotating Mach. (2004)

[6] Y.B. Kazakov, N.A. Morozov, S.A. Nesterov, J. Magn. Magn. Mater. 431, 269 (2017)

[7] X. Wang, H. Li, W. Lu, G. Meng, J. Tribol. 139, 051701 (2017)

[8] X. Wang, H. Li, G. Meng, Tribol. Int. 114, 1 (2017)

[9] J. Wang, N. Feng, G. Meng, E.J. Hahn, J. Intell. Mater. Syst. Struct. 17, 353 (2006)

[10] A.S. Das, J.K. Dutt, K. Ray, Appl. Math. Model. 34, 2353 (2010)

[11] E.A. Ribeiro, J.T. Pereira, C.A. Bavastri, J. Sound Vib. Complete, 43 (2015)

[12] T. Aoyama, I. Inasaki, CIRP Ann. 46, 309 (1997)

[13] E. W. Williams, S. G. Rigby, J. L. Sproston, R. Stanway, J. Non-Newton. Fluid Mech. 47, 221 (1993)

[14] O.O. Christidi-Loumpasefski, I. Tzifas, P.G. Nikolakopoulos, C.A. Papadopoulos, Proc. Inst. Mech. Eng. Part K J. Multi-Body Dyn. 1464419317725932 (2017)

[15] P.G. Nikolakopoulos, C.A. Papadopoulos, Int. J. Mod. Phys. B 10, 3045 (1996)

[16] J.M. Vance, D. Ying, J. Eng. Gas Turbines Power 122, 337 (2000)

[17] S. Lim, S.M. Park, K.I. Kim, J. Sound Vib. 284, 685 (2005)

[18] A. Bouzidane, M. Thomas, Comput. Struct. 86, 463 (2008)

[19] S.C. Sharma, C.B. Khatri, J. Intell. Mater. Syst. Struct. 1045389X17742731 (2017)

[20] G. Adiletta, A.R. Guido, C. Rossi, Nonlinear Dyn. 10, 251 (1996)

[21] C. Dorier, J. Tichy, J. Non-Newton. Fluid Mech. 45, 291 (1992)

[22] P.G. Nikolakopoulos, C.A. Papadopoulos, Tribol. Int. 31, 225 (1998)

[23] P. Bonello, Proc. Inst. Mech. Eng. Part J J. Eng. Tribol. 223, 79 (2009) 